\title{
System vulnerability and risk assessment of railway systems to flooding
}

11 ABSTRACT: Floods have negative effects on the reliable operation of transportation

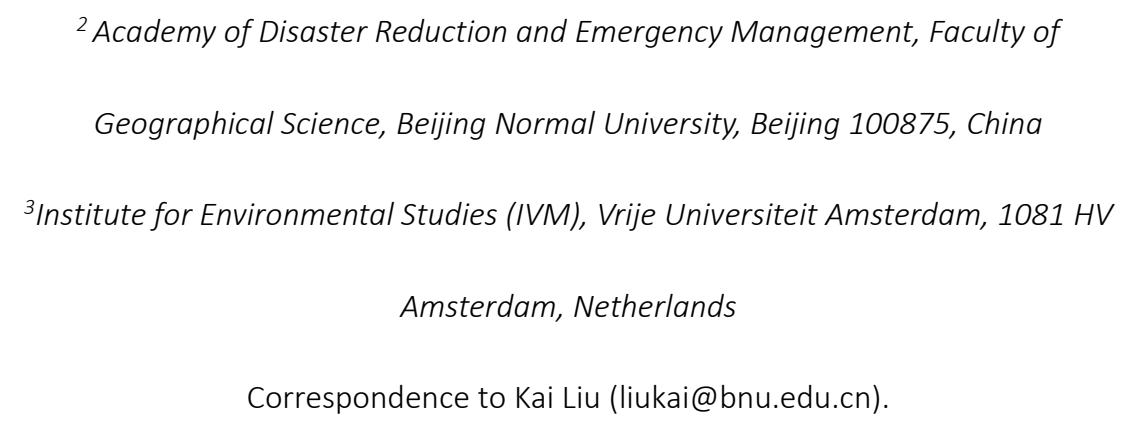


1 events in the Yangtze River Basin show the largest impact on the national railway system,

2 with approximately $40 \%$ of the national daily trains being affected by a 100 -year flood

3 event in that basin. At the national level, the average number of daily affected trains

4 and passengers for the national system are approximately 200 trips and 165,000 people

$5 \quad(2.7 \%$ and $2.8 \%$ of the total daily numbers of trips and passengers), respectively. In

6 addition, the mean average increased time for detoured trains reaches approximately

7 five hours. The event-based approach presented in this study shows how we can

8 identify critical hotspots within a complex network, taking the first steps in developing

9 climate-resilient infrastructure.

10 KEYWORDS: river basin flooding; railway system; risk assessment; system vulnerability

\section{1. Introduction}

12 Floods can have negative effects on transportation systems through both the

13 destruction of physical infrastructure and the disruption of freight and traffic flows

14 (Reed, 2004; Moran et al., 2010; Benn, 2013; Kellermann et al., 2015). For example,

15 during the Tbilisi (Georgia) floods in June 2015, the estimated damage in terms of

16 replacing affected assets was 14.8 million USD, whilst losses related to increases in

17 travel time and higher operating costs were estimated at approximately three million

18 USD (up until autumn 2015) (GFDRR, 2015). In May and June 2013, the Austrian Federal

19 Railways faced severe damage by the major floods in central Europe, with a total cost

20 of more than 84 million USD. The event caused extensive damage to track structures 
1 and also caused widespread service disruptions, despite many protective actions that

2 had been adopted ahead of time (Kellermann et al., 2016). In China, over 2146 rail

3 service disruption events and over 20,825 hours of discontinued service due to flooding

4 were reported from 2000 to 2016 (Editorial Board of China Railway Yearbook, 2001-

5 2017). In 2016, the direct economic loss of the Chinese railway system caused by floods

6 was approximately 80 million USD (Editorial Board of China Railway Yearbook, 2001-

7 2017). As such, there is a clear need to evaluate the vulnerability of the transportation

8 system to extreme flood hazards and to identify high-risk transportation components

9 to make the transportation systems safer and more effective for operation and

10 maintenance.

11 Many studies have investigated flood impacts on transportation systems, focusing on

12 either flood vulnerability of assets (Kellermann et al., 2015; Pregnolato et al., 2017;

13 Singh et al., 2018; Koks et al., 2019) or the risk to the entire system (Gil and Steinbach,

14 2008; Kellermann et al., 2016; Lamb et al., 2019). In these studies, flood vulnerability is

15 usually defined as the relationship between the characteristics of the transportation

16 components (i.e., the physical structure, traffic flow and traffic velocity) and the

17 variables characterizing the intensity of the flood hazard (i.e., flood depth and flood

18 velocity) (Pregnolato et al., 2017). However, as major river floods are usually driven by

19 large-scale atmospheric circulations (Prudhomme and Genevier, 2011; Lavers et al.,

20 2013) and affect large areas, they can disrupt several components concurrently across

21 a network system (Becker and Grünewald, 2003; Kundzewicz et al., 2013). Within a 
1 network system, the impact on operational performance is often the result of failure of

2 multiple components in the aftermath of an event (Gong et al., 2017). As such, a

3 system-level perspective is essential to properly assess transportation system

4 vulnerability due to flooding.

5 Some studies have assessed transportation vulnerability to natural hazards from a

6 system-level perspective (Chang et al., 2010; Hong et al., 2015). Chang et al. (2010)

7 investigated the potential impacts of climate change on travel disruption in the

8 metropolitan area of Portland, Oregon. They combined a hydrologic, hydraulic model

9 and a travel forecast model to process their study. Hong et al. (2015) assessed the

10 Chinese railway system's vulnerability in terms of traffic flow loss based on historical

11 flood events from 1981 to 2010. Unfortunately, due to the widespread lack of

12 appropriate historical flood hazard data and computational issues with running large-

13 scale hydraulic models (Sene 2008; Chang et al. 2010), research so far has been carried

14 out only on a case-study basis where historical scenarios are available (Hong et al.,

15 2015). However, for inter-city and inter-country trade, national and global-scale

16 transportation systems have flourished in recent decades. Examples include Pan-

17 European transportation corridors (Janic and Vleugel, 2012) and the railway system of

18 the Belt and Road Initiative (Yang et al. 2018); therefore, large-scale flood event data

19 and methods should be improved to assess system-level vulnerability and risk on

20 operational performance for such large spatial transportation systems.

21 The recent development of global flood hazard maps (Alfieri et al., 2013; Hirabayashi 
1 et al., 2013; Ward et al., 2013; Sampson et al., 2015;Dottori et al., 2016) has paved the

2 way for performing large-scale flood risk assessments. These global flood hazard maps

3 have been widely applied to assess the global risk to flooding in terms of population

4 (Ward et al. 2013; Arnell et al. 2016; Dottori et al. 2016), gross domestic product (GDP)

5 (Ward et al., 2013; Winsemius et al., 2013), economic damage (Ward et al., 2013;

6 Dottori et al., 2016; Winsemius et al., 2016; Ward et al., 2017), and transportation

7 infrastructure (Koks et al., 2019). Koks et al. (2019), for example, assessed the direct

8 economic damage to transportation infrastructure assets using a conventional damage

9 assessment approach through asset-specific fragility curves based on global flood data.

10 Studies such as these facilitate a better understanding of the impacts of flood hazards

11 on large-scale transportation systems and provide up-to-date knowledge on risk 12 analysis frameworks.

13 This study aims to develop a framework to quantify the system vulnerability and risk

14 in transportation systems in terms of operational performance loss under large-scale

15 flood hazards. System vulnerability in this study is represented as the system

16 performance loss with different flood intensities. Most studies use regional- or national-

17 scale flood footprints, which show the flood depth for a given return period in that area.

18 In reality, the presented floods in such as a flood footprint may not all happen at the

19 same time. When assessing possible cascading effects, the use of independent flood

20 events is therefore necessary (Nones and Pescaroli, 2016). As such, we develop a

21 method for generating a set of independent flood events at the national and river basin 

method. We illustrate our methodology by applying it to the Chinese railway system. framework for the evaluation of system vulnerability and risk of flood hazards to

5 transportation systems and use the Chinese railway system for application, including how to generate flood events, define the network system for the transportation system,

7 calculate system vulnerability metrics, and quantify flood risk. Section 3 presents the

8 main findings and results. Section 4 and Section 5 provide the discussion and conclusion,

9 respectively, to this article.

\section{2. Data and method}

11 Flood risk can be defined as a function of flood hazard, exposure and its related

12 vulnerability. A flood hazard is usually characterised by its intensity and occurrence

13 probability; exposure refers to the population and assets exposed to flooding; and

14 vulnerability is often defined as the loss ratio of people or assets suffered to different

15 intensity of hazard (Gouldby and Samuels, 2009; Haimes, 2009; UNISDR, 2011;

16 Winsemius et al., 2013). In this work, exposure is represented by the railway network

17 exposed to the flood hazard. Asset vulnerability is defined as the failure of a railway

18 asset based on the design standard and is expressed as a failure threshold. If the failure

19 threshold is exceeded, the service of the component is assumed to be disrupted,

20 resulting in a $100 \%$ performance loss of that asset. System vulnerability is represented 
1 as the system performance loss with different flood intensities. Risk is calculated as the

2 expected annual performance loss at the national and provincial levels.

3 Figure 1 presents an overview of the framework used in this study. First, we generate

4 a national- and river basin-scale flood event set. To do this, we use flood hazard maps

5 for different return periods at the national scale, taken from a global flood hazard model.

6 We then divide these into flood hazard maps for the major river basins and use a curve-

7 fitting method to estimate the flood depth for any return period for any cell. We then

8 apply a Monte Carlo sampling method (Metropolis 1987) to generate the flood events

9 per river basin and aggregate these events to the national scale. Second, we define the

10 railway system as a network using network theory (Newman, 2010). Third, we intersect

11 the flood events with the railway network to identify the disrupted segments in the

12 railway system based on a pre-defined failure threshold. In the last part of our analysis,

13 we assess the system vulnerability and risk in terms of several performance loss metrics,

14 including the daily cancelled trains and cancelled passengers, the daily detoured trains

15 and detoured passengers, the daily affected trains and affected passengers, as well as

16 the total increased time and the average increased time for the detoured trains. We

17 also analyse the parameters in the failure threshold sensitivity to the risk result and the

18 related risk uncertainty. 

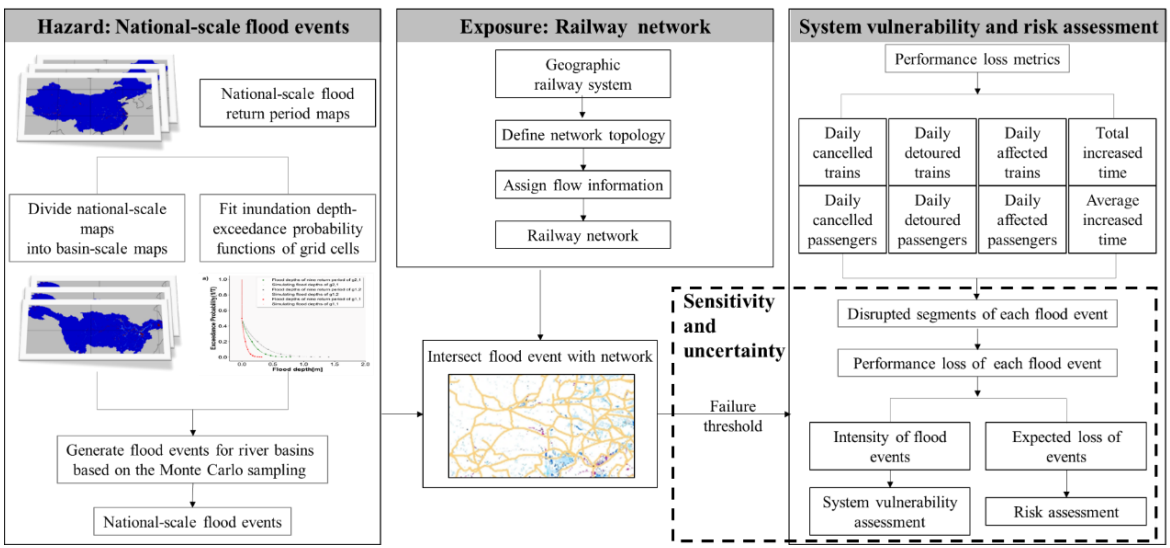

Fig. 1 Methodology of the flood system vulnerability and risk assessment of railway infrastructure. Railway geometries (C) OpenStreetMap contributors 2019. Distributed under the Open Data Commons Open Database License (ODbL) v1.0.

\subsection{National-scale flood event generation}

To ensure the estimation is as accurate as possible for an event-based flood risk assessment, a large number of independent flood events are required (Speight et al., 2017; Wu, 2019; Zhu et al., 2020). In this study, we apply a curve-fitting method and a Monte Carlo sampling method to generate independent flood events using global flood hazard maps from GLOFRIS for multiple return periods (Ward et al., 2013). In brief, for each grid cell, we obtain the flood depth from the flood hazard maps for nine different return periods (2-1000 years). We then fit an inundation depth-exceedance probability function through these data points, which is used to estimate the flood depths for any return period. Based on these functions per cell, we apply a Monte Carlo sampling method to produce basin-specific flood events, which are further combined into a national independent flood event set (see Section 2.1.3). In this study, we assume that 
1 a flood event within one basin will produce a flood with the same intensity (return

2 period) within that entire basin, whilst we assume that floods between different basins

3 are independent of each other (Fraiture, 2007; Rojas et al., 2013). In the following

4 subsections, we describe the input flood hazard maps, the function fitting procedure,

5 and the Monte Carlo analysis in more detail.

\section{$6 \quad 2.1 .1$ Input flood hazard maps}

7 Our flood hazard data are extracted from the GLOFRIS global fluvial flood hazard

8 maps of Winsemius et al. (2013), which are developed using the methods provided in

9 Ward et al. (2013) and Winsemius et al. (2013). The GLOFRIS flood hazard dataset is a

10 global 30-arcsecond (ca. 1-km) resolution gridded dataset. Hazard maps are provided

11 for nine return periods $(2,5,10,25,50,100,250,500$, and 1000 years). We divide China

12 into nine major river basins (Fig. 3) according to the main river system from the Data

13 Center for Resources and Environmental Sciences, Chinese Academy of Sciences, which

14 is accessible from the Resource and Environment Data Cloud Platform

15 (http://www.resdc.cn/, last access: 19 May 2020): the Continental Basin, Haihe River

16 Basin, Huaihe River Basin, Pearl River Basin, Songhua and Liaohe River Basin, Southeast

17 Basin, Southwest Basin, Yellow River Basin and Yangtze River Basin. As such, we extract

18 the flood hazard data for each of these river basins.

\section{$19 \quad 2.1 .2$ Fitting procedure}

20 For each grid cell, the GLOFRIS maps estimate the flood depth for the nine 
1 aforementioned return periods. To estimate the flood depth for any return period, we

2 fit a quadratic spline function to develop an inundation depth-exceedance probability

3 function $(p)$ for each grid cell (Marsden, 1974; Vandebogert, 2017; Meshram et al.,

4 2018). The quadratic spline is a method that uses a piecewise quadratic function to

5 obtain the best-fitting curves. This interpolation method allows us to obtain a smooth continuous curve through the provided flood depths for the different return periods.

7 The method is applied as follows. For each grid cell, the annual exceedance

8 probability flood depth $D_{T}$ is calculated by Eq. 1:

9

11 is the exceedance probability of $D_{T} . D_{T}$ is between $\left[D_{1}, D_{1000}\right]$, with $D_{1}=D_{2} \leq$

$$
P\left(D_{T}\right)=\frac{1}{T}
$$

where $D_{T}$ is the magnitude of a flood depth with return period of $T$-year, $P\left(D_{T}\right)$ $D_{5} \ldots \leq D_{1000}$. We assume that $D_{1}$ is equal to zero (i.e., 1-year event with a flood depth of $0 \mathrm{~m}$ ) and is the same as that of a 2-year event (the lowest return period in the GLOFRIS dataset). Let $\operatorname{Pr}\left(D_{T}\right)$ denote a quadratic, continuously differentiable function of $P\left(D_{T}\right)$. Then, by definition:

$$
\operatorname{Pr}\left(D_{T}\right)=a D_{T}^{2}+b D_{T}+c
$$

For each interval of grid cell $g_{x, y}$, we can obtain its piecewise quadratic function by

Eq. 3:

$$
\operatorname{Pr}_{x, y}\left(D_{T}\right)=\left\{\begin{array}{c}
\operatorname{Pr}_{x, y}^{1}\left(D_{T}\right)=a_{1} D_{T}^{2}+b_{1} D_{T}+c_{1} D_{T} \in\left[D_{1}, D_{1-T}\right] \\
\operatorname{Pr}_{x, y}^{2}\left(D_{T}\right)=a_{2} D_{T}^{2}+b_{2} D_{T}+c_{2} D_{T} \in\left[D_{1-T}, D_{2-T}\right] \\
\cdots \\
\operatorname{Pr}_{x, y}^{p}\left(D_{T}\right)=a_{p} D_{T}{ }^{2}+b_{p} D_{T}+c_{p} D_{T} \in\left[D_{p-1-T}, D_{p-T}\right]
\end{array}\right.
$$

where $\operatorname{Pr}_{x, y}\left(D_{T}\right)$ is a set of continuous inundation depth-exceedance probability 
1 functions consisting of $p$ continuous quadratic functions. For

$2 \mathrm{a}\left(\mathrm{a}_{1}, \mathrm{a}_{2}, \ldots, \mathrm{a}_{p}\right), \mathrm{b}\left(b_{1}, b_{2}, \ldots, b_{p}\right), \mathrm{c}\left(c_{1}, c_{2}, \ldots, c_{p}\right) \in \mathrm{R}$, we can calculate these constants

3 by bracketing the critical point of $P\left(D_{T}\right)$ and derivative of the function $\operatorname{Pr}_{x, y}\left(D_{T}\right)$;

4 details on the interpolation methods can be found in a previous study by Sun and Yuan

5 (2006). We assume that only one event occurs per year in each basin. Examples of the

6 inundation depth-exceedance probability function of grid cells are shown in Fig. 2a.

$7 \quad 2.1 .3$ Simulation procedure

8 To produce a time-series of flood events based on the created inundation depth-

9 exceedance probability functions (Section 2.1.2), we use a Monte Carlo sampling

10 method. The basic idea of the Monte Carlo sampling method is that when the number

11 of simulations is sufficiently large, the frequency of an event approximates the

12 probability of the occurrence of the event (Baker, 2008; Speight et al., 2017). The flood

13 event generation procedure is presented in Fig. 2 and Appendix Fig. A1 and can be

14 summarized in two steps. First, we generate a set of independent events at the basin

15 scale. For each event $E_{j}^{i}$, and for each basin $B_{j}$, a random number $P_{j}^{i}$ between 0 and

161 is generated from a uniform distribution. The flood depth of the cells in basin for

17 event $E_{j}^{i}$ can be calculated using $P_{j}^{i}$ and the inundation depth-exceedance

18 probability function based on the assumption that a flood event in one basin will

19 produce a flood with the same intensity. This concept is presented in Fig. 2a-b. Second,

20 we generate a set of national-scale independent flood events. For a national-scale flood 
1 event, basin-specific floods of nine basins can be randomly combined into a national-

2 scale flood by assuming independence between the flood events among different

3 basins, as presented in Fig. 2c-d.

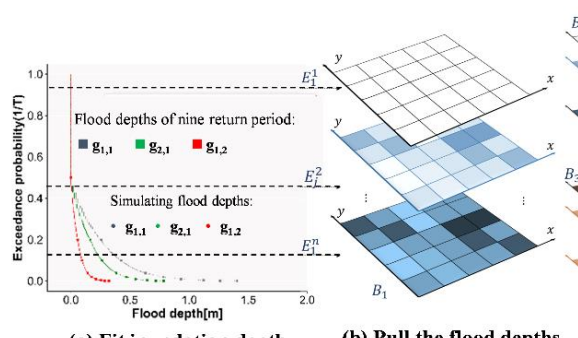

$\begin{array}{ll}\text { (a) Fit inundation depth- } & \text { (b) Pull the flood depths }\end{array}$

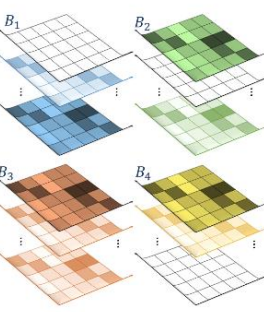

(c) Generate basin-specific flood events

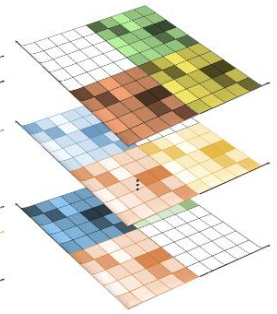

(d) Combine basin-specific flood events into national-scale events

Fig. 2 A flowchart of national-scale flood event generation. $E_{1}^{1}$ (the top layer in (b)) is a flood event in basin $B_{1}$, where $P_{1}^{1}=0.93 ; E_{1}^{2}$ (the middle layer in (b)) is a flood event in basin $B_{1}$, where $P_{1}^{2}=0.45$; and $E_{1}^{3}$ (the lower layer in (b)) is a flood event in basin $B_{1}$, where $P_{1}^{3}=0.17$. The upper-left layers in (c) are a basin-scale flood set of basin $B_{1}$, the upper-right layers in (c) are a basin-scale flood set of basin $B_{2}$, the lower-left layers in (c) are a basin-scale flood set of basin $B_{3}$, and the lower-right layers in (c) are a basin-scale flood set of basin $B_{4}$. The top layer in (d) is combined with the top four layers in (c) (the four basin-scale floods of basin $B_{1}, B_{2}, B_{3}$ and $B_{4}$ combine into a national-scale flood event).

For each year, we assume that within each basin, only one flood event can occur. For each basin to obtain 10,000-year events (we assume that 10,000-year of events are sufficient to cover almost all probable scenarios), we therefore apply a Monte Carlo method to sample 10,000 exceedance probabilities. For each of these exceedance probabilities, we estimate the inundation depth for each cell within that basin (i.e., assuming that the exceedance probability is the same throughout the entire basin). We 
1 repeat this procedure for each basin, which results in a 10,000-year set of flood events

2 for each basin. We then combine these sets into a national scale flood event set by

3 assuming independence between the flood events in the different river basins (Fig. $2 \mathrm{~d}$ ).

4 Hence, for each of the 10,000 years, we simply take the estimated flood depths for each

5 basin. For example, in year 1 , basin 1 may have an exceedance probability of 0.5 , whilst

6 basin 2 may have an exceedance probability of 0.98 . For year 1 , the resulting national-

7 scale flood map would therefore have values for a flood event with an exceedance

8 probability of 0.5 in basin 1 , a flood event with an exceedance probability of 0.98 in

9 basin 2, and so forth. This procedure results in a 10,000-year national-scale flood event

10 set.

11 We also assess the system vulnerability by calculating the impacts that could occur

12 throughout China if a flood with a given return period were to occur within an individual

13 basin. To do this, for each basin and each return period we draw 10,000 events for all

14 other basins assuming independence. In total, this leads to a set of 810,000 events

15 (10,000 events $\times 9$ return periods $\times 9$ basins $).$

\section{$16 \quad 2.2$ Railway network building}

17 Railway systems are commonly represented through spatially explicit networks as an

18 analogy for their structure and flows (Rodrigue, 2016). This network representation can

19 be used to calculate system performance metrics based on network theory. In this work,

20 the Chinese railway system was modelled as a directed weighted network, which 
1 consists of a group of nodes (stations) and connected by edges (railway lines) with daily

2 train trips, where the edges have a travel direction associated with them. To build the

3 Chinese railway network, we use the geographic information of railway system from

4 OpenStreetMap (OSM) and the timetable data including daily number of trains and

5 associated routes from the Railway Service Website (Liu et al., 2018; Zhu et al., 2020).

6 As our method is primarily concerned with flood risk along rail segments between cities

7 and not within cities, for simplicity, we combine multi-stations into one node using the

8 location of the highest capacity station in each city. In total, 2240 nodes are combined

9 into 1790 nodes. The final extracted railway network has a total length of 90,600 km for

10 (merged parallel) lines connecting two identical stations, consisting of 1973 edges and

111790 nodes (Fig. 3). Figure 3 shows the spatial distribution of the railway network and

12 average daily numbers of trains. Topology and traffic flows vary greatly in spatial apace.

13 The network density, reduces greatly moving from Eastern China to Western China. For

14 the traffic flow, the railways connect large cities, like the railways from Beijing to

15 Guangzhou, Harbin and Shanghai, and railway from Shanghai to Changsha have higher 16 flows. 


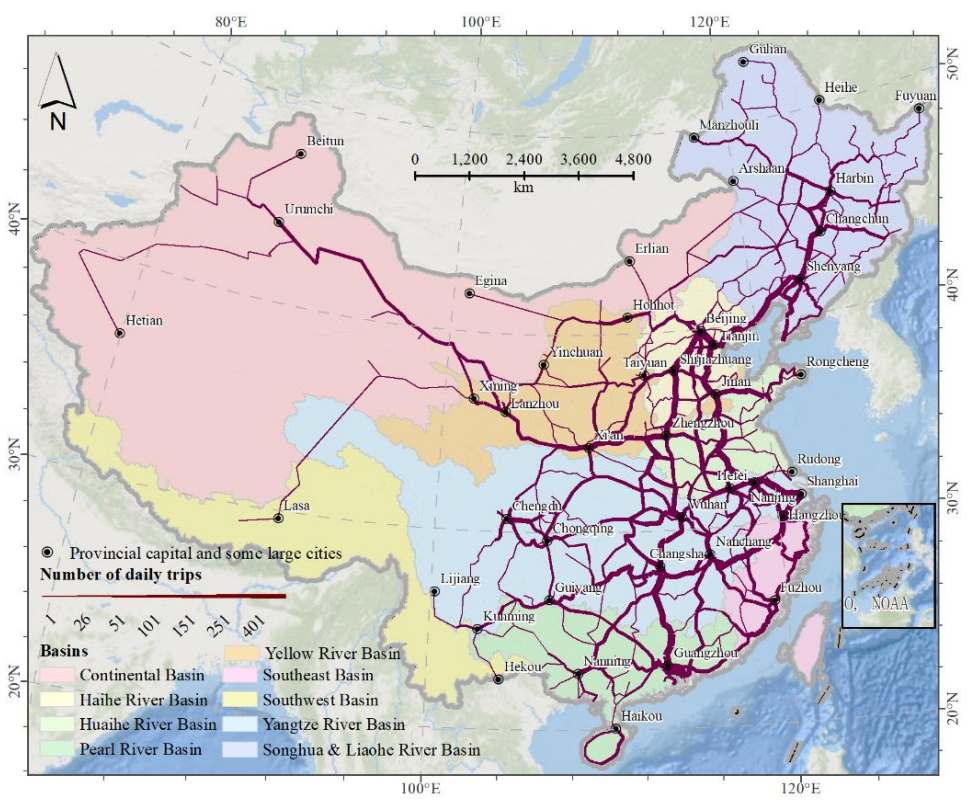

Fig. 3 The spatial distribution of the railway network and average daily numbers of trains.

3

The river basins layer comes from the Data Center for Resources and Environmental Sciences, Chinese Academy of Sciences, which is accessible from the Resource and Environment Data Cloud Platform (http://www.resdc.cn/, last access: 19 May 2020). Railway geometries (O) OpenStreetMap contributors 2019. Distributed under the Open Data Commons Open Database License (ODbL) v1.0. The timetable data included the daily number of trains and associated routes from the Railway Service Website (Liu et al., 2018).

\subsection{Failure condition based on an event}

We assume that a railway is impassable when the water level on the railway line is higher than the failure threshold $W d$ of the railway service after drainage (CRPH, 2012; Espinet et al., 2018). The water level after drainage $W L_{x, y}$ of grid cell $g_{x, y}$ is calculated by Eq. 4: 

capacity rate.

5 The rail segment $l_{i j}$ between two stations failure condition is defined by Equations 65 and 6:

$9 \quad F c_{i j}$ is the failure condition of component $l_{i j}$, which has two states, namely, normal

10 (denoted by 1 ) and disrupted (denoted by 0 ), resulting in $100 \%$ disruption. $Z(x y)$ is

11 the failure condition of grid cell $g_{x, y}$; when the water level after drainage is larger than

$12 W d, Z(x y)=0$; otherwise, $Z(x y)=1$.

13 In this study, we consider a failure threshold of $0.2 \mathrm{~m}$ after drainage, according to the 14 railway transportation emergency plan (CRPH, 2012; Espinet et al., 2018). The flood 15 design standard of the culverts, bridge and embankments of the Chinese national railway system is designed for 100 year in China, according to the standard for flood control (CRPH, 2016). Furthermore, we assume that the drainage capacity rate is 0.8 of water level of the design standard, and it reduces the total amount of water that the railway structure can actually drain (TB 10001, 2016; Espinet et al., 2018).

Failure hotspots of railway segments $l_{i j}$ can be found by the annual failure 


$$
A F_{i j}=\frac{\sum_{e}^{E} F C_{i j}^{e}}{N}
$$
event $e$.

\section{$5 \quad 2.4$ Calculating system vulnerability and risk}

6

7

8

9

10

\subsubsection{Performance loss metrics}

\section{Daily affected trains and the associated daily affected passengers}

Once a flood occurs, trains may be affected in two ways: (i) increased travel time; or (ii) cancellation. The number of daily affected trains $N_{e}^{\text {tol }}$ is calculated by Eq. 8:

$$
N_{e}^{t o l}=N_{e}^{c}+N_{e}^{d}
$$

Where $N_{e}^{c}$ the number of daily is cancelled trains and $N_{e}^{d}$ is the number of daily detoured trains after a flood event.

We assume that the average number of passengers is $80 \%$ of the train's capacity (Wei et al., 2017)(Rezvani et al., 2015)(Rezvani et al., 2015)(Rezvani et al., 2015)(Rezvani et al., 2015). As such, the number of affected passengers $P_{e}^{\text {tol }}$ can be defined by Eq. 9:

$$
P_{e}^{t o l}=\sum_{i}^{\left(N_{e}^{c}+N_{e}^{d}\right)} C A_{i} * 0.8
$$

where $C A_{i}$ is the capacity of the ith train.

\section{Daily detoured trains and the associated daily detoured passengers}

Once a flood occurs, some trains will detour to complete their journeys. The daily detoured trains $N_{e}^{d}$ can be calculated based on four assumptions as follows (in order 
1 of descending priority), which is also presented in Appendix Fig. A2:

2 (1) Stations are not repeated along the routes;

3 (2) The train passes the largest number of original stations along the detoured

4 route;

(3) The detour with the smallest increase in travel time is selected; 24 hours.

8 the daily detoured passengers $P_{e}^{d}$ can be defined by Eq. 10:

$$
P_{e}^{d}=\sum_{i}^{\left(N_{e}^{d}\right)} C A_{i} * 0.8
$$

10 where $N_{d}$ is the daily detoured trains and $C A_{i}$ is the capacity of the $i t h$ train.

12 The total increased time $T_{e}^{\text {tol }}$ for detoured trains is calculated by Eq. 11:

$$
T_{e}^{t o l}=\sum_{i}^{N_{d}} T_{i}^{e}-\sum_{i}^{N_{d}} T_{i}
$$
original travelling time of the ith train.

17 The average increased time is calculated by Eq. 12:

$$
T_{e}^{\text {ave }}=\frac{T_{e}^{\text {tol }}}{N_{e}^{d}}
$$

19 where $T_{e}^{\text {ave }}$ is the average increased time under flood event e and $N_{d}$ is the 20 number of detoured trains. 

cancelled trains $N_{e}^{c}$ is calculated by Eq. 13:

$$
N_{e}^{c}=N_{S}-N_{e}^{S}
$$

8 in the system.

9 Daily cancelled passengers $P_{e}^{c}$ can be defined by Eq. 14:

$$
P_{e}^{c}=\sum_{i}^{\left(N_{e}^{c}\right)} C A_{i} * 0.8
$$

11 where $N_{c}$ is the daily cancelled trains and $C A_{i}$ is the capacity of the $i t h$ train.

\section{2.4.2 Calculating system vulnerability and risk} curves are generated to present the relationship between performance loss and flood

15 intensity (return period). We use the expected daily affected trains, cancelled trains, detoured trains, affected passengers and increased time for detoured trains to present the flood risk to the railway system according to Eq. 15:

$$
A R_{S}=\frac{\sum_{e}^{E} V_{e}}{N}
$$

19 where $A R_{S}$ is the expected daily flood risk level to the railway system, $E$ is the N-

20 event flood catalogue, and $V_{e}$ is the performance loss metric, 
1 i.e., $N_{e}^{d}, N_{e}^{c}, N_{e}^{t o l}, P_{e}^{d}, P_{e}^{c}, P_{e}^{t o l}, T_{e}^{t o l}$, and $T_{e}^{a v e}$ under flood event $e$, which is defined in

2 Eqs. 9-14.

\section{$3 \quad 2.5$ Uncertainty and sensitivity analysis}

4 By applying an uncertainty analysis (UA), we identified the range of model output for

5 imprecisely known input parameters (De Moel et al., 2012). A sensitivity analysis (SA)

6 aims to determine the parameter effect on the model output (Koks and Haer, 2020).

7 Parameters with greater effect should attract more additional attention to deal with the

8 uncertainty they bring (Koks and Haer, 2020; De Moel et al., 2012). Detailed methods

9 of uncertainty and sensitivity analysis can be found in previous studies by De Moel

10 (2011) and Koks and Haer (2020).

11 In this study, we make assumptions on the train disruption threshold using three

12 parameters (the water level failure threshold, drainage capacity rate, and design

13 standard) based on emergency code and design code standards (CRPH 2012). However,

14 it should be noted that these standards are not known exactly for each asset and will

15 change over time, such as dynamically changing protection standards and ageing

16 infrastructure. Within a railway system, a lot of different asset types exist, with varying

17 design standards. This implies that the capacity to cope with the hazard does vary from

18 location to location. As such, it is worthwhile to perform a sensitivity analysis on these

19 key parameters (De Moel and Aerts, 2011; Horacio et al., 2019). Hence, we perform an

20 uncertainty and global sensitivity analysis in which we assess the performance loss 
1 metrics for a range of different values for these parameters. For water level failure, we

2 use a range between 0.1 and $0.5 \mathrm{~m}$. For the drainage capacity rate, we use a range

3 between 0.7 and 0.9 , and for the design standards, we use a range between 50 and 100

4 years. The list of all assumptions taken in this study and their range in the sensitivity

5 analysis can be found in appendix. In total, we create a set of 1000 different parameter

6 value combinations in the sample space.

\section{$7 \quad 3$ Results}

\section{$8 \quad 3.1$ Failure hotspots of railway segments}

9 The annual failure probability of the network segments is shown in Fig. 4 and is calculated based on the 10,000-year national flood event set. The results show a clear regional differentiation (Fig. 4a). Areas with high annual failure probabilities are mainly

12 located in the Yangtze River Basin, Southeast Basin, and Pearl River Basin areas. These three basins have a humid subtropical climate and high precipitation levels in the rainy

14 season during the summer; and these areas also have the highest railway density (Fig.

15 3), mostly across rivers and located on flat area in China, which makes these railway

16 lines susceptible to flood hazards.

17 Figure $4 b$ shows the percentage of the length of railway lines that fall into each failure

18 probability category for the national- and basin-level analyses. Nationally, the failure

19 probability is greater than 0 for more than $55 \%$ of the total length of the railway lines.

20 This percentage is heterogeneous across different river basins: it is highest in the 
1 Southeast Basin, followed by the Pearl River Basin and the Yangtze River Basin.

2 Nationally, $6.8 \%$ of the length of the railway lines has a failure probability greater than

30.02 , with the highest proportions in the Yangtze River, Yellow River, and Southeast

4 Basins, with $12.5 \%, 10 \%$ and $7.2 \%$, respectively.
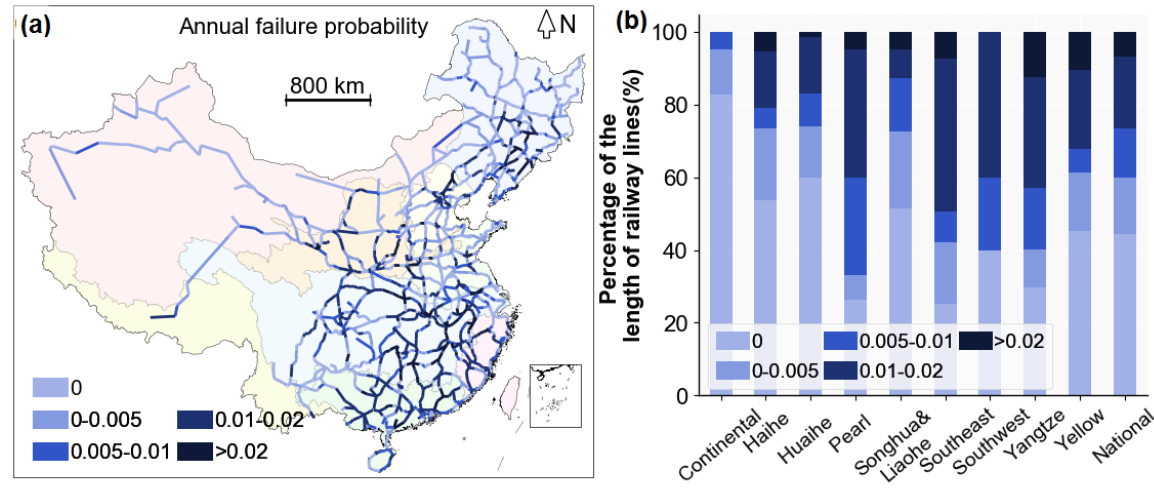

5

Fig. 4 (a) Annual failure probability map of the network segments affected by floods and (b) the percentage of the length of railway lines for different failure probability categories per river basin. Railway geometries (C) OpenStreetMap contributors 2019. Distributed under the Open Data Commons Open Database License (ODbL) v1.0.

\subsection{Risk analysis of the Chinese railway system}

The performance loss distribution curves of the railway system using the 10,000 -year national-scale flood set are presented in Fig. 5. The results show that approximately $85 \%$ of the flood events have little effect (less than 0.01 of the daily trains and passengers) on the railway system from the perspective of all the performance metrics. For the daily affected trains, the absolute maximum number can reach 4200 , and the average number is approximately 200 trips; these values represent $59 \%$ and $2.7 \%$ of the number of the 
1 daily trains. For the daily affected passengers, the absolute maximum number can reach

$23,500,000$, and the average number is approximately 165,000 people ( $60 \%$ and 2.8 of the

3 number of the daily passengers). In addition, the largest average increased time for detoured

4 trains can reach 14 hours and the mean average increased time for detoured trains is

5 approximately 5 hours.

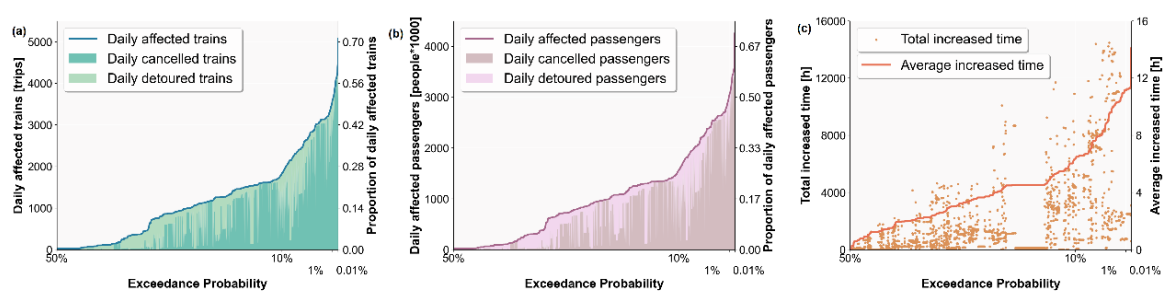

Fig. 5 Exceedance probability-performance loss curves

8 The performance losses per province of the railway system are presented in Fig. 6 for

9 a range of metrics. The risk differs considerably between regions when expressed in different risk metrics. When examining the metrics of the daily affected trains and

11 affected passengers, we find that the provinces in Central China, such as Henan, Hubei

12 and Anhui, have the highest absolute and relative risks, estimated to be over 40 daily

13 affected trains (4.5\% relative to the number of the province's daily trains) and more

14 than 35,000 daily affected passengers (3.5\% relative to the number of the province's

15 daily passengers). Interestingly, some provinces, such as Tibet Province, have a low risk

16 in absolute terms but a high risk in relative terms because the Tibet Province has the

17 smallest rail network and rail traffic density; only one line (i.e., Qinghai-Tibet Railway)

18 crosses this region, which is therefore highly vulnerable to even a low-frequency flood 
1 hazard. Guangdong Province has the opposite results, with high risk in absolute terms

2 and low risk in relative terms due to the large rail network and rail traffic density, which

3 make the railway system more robust even with a high flood failure probability. The total

4 and average increased time for detoured trains show contrasting results. The high risk

5 in terms of the total increased time is mostly distributed in East China, whereas the

6 highest average increased time is distributed in western provinces such as Xinjiang and

7 Tibet Provinces. From Eastern China to Western China, the traffic flow becomes

8 significantly lower; more trains can be detoured with less time per trip in East China,

9 and in the western provinces, fewer trains can be detoured but with more time per trip.
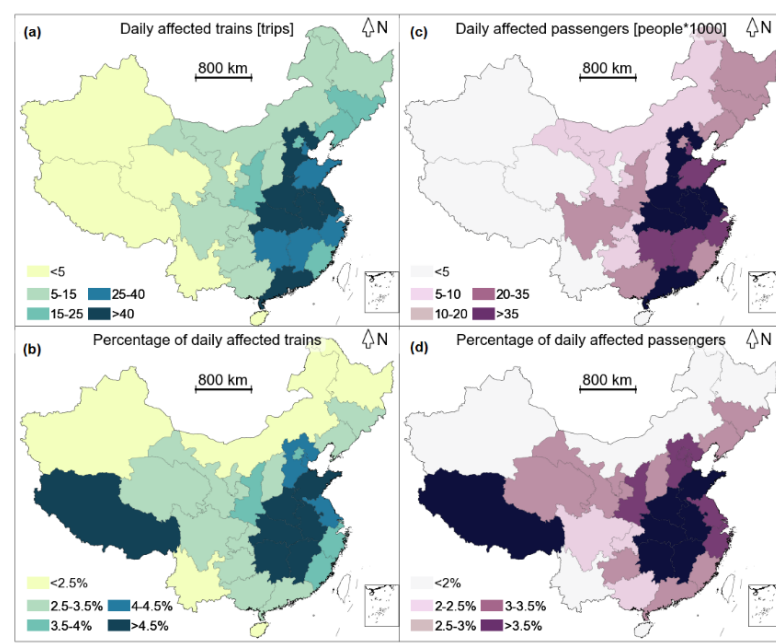

Fig. 6 Performance loss of the railway system per province.
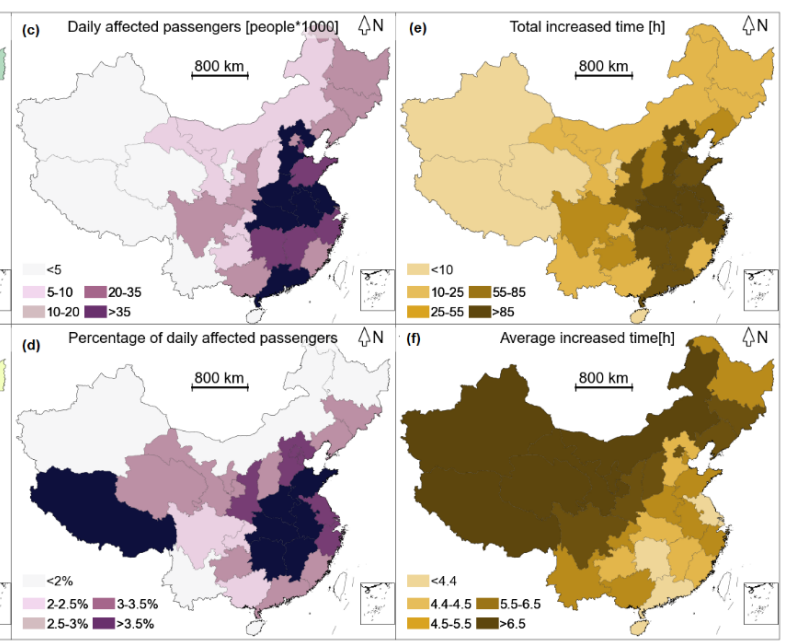
(a) The daily affected trains in absolute terms; (b) the daily affected trains relative to the number of the province's daily trains; (c) the daily affected passengers in absolute terms; (d) the daily affected passengers relative to the number of the province's daily passengers; (e) the daily total increased time for the detoured trains per province; and (f) daily average increased time for the detoured trains per province. Appendix Fig. A3 provides the risk map of detoured 
and cancelled trains and detoured and cancelled passengers. Appendix Fig. A4 provides

4 and can be classified as particularly vulnerable provinces. Anhui Province, for example,

5 has one of the highest absolute and relative levels of risk to trains and passengers in Fig.

6 6a-d but also has the highest total increased time in Fig. 6e. Hubei Province shows one

7 of the highest absolute and relative levels of risk to trains and passengers in Fig. 6a-d.

8 Jiangsu Province has the highest absolute levels of risk to trains and passengers in Fig.

$96 \mathrm{a}$ and $\mathrm{c}$ and one of the highest total increased time in Fig. 6e. These provinces are at

10 the highest risk compared to the other provinces.

\subsection{System vulnerability of the Chinese railway system}

12 Figure 7 presents system vulnerability curves based on the 810,000 simulated flood

13 events and shows the performance loss metrics (namely, the percentage of daily

14 affected trains and increased time) plotted against the return periods. The bottom-right

15 plots for subfigures $a$ and $b$ show the national results, whilst the other figures show the

16 results for each river basin. The colour shade represents the distribution of the flood

17 performance loss, where the lines refer to the median performance loss value and the

18 bounded lines refer to the 10th and 90th percentiles. The low-impact events cause the

19 median values to be the same as the lower bound for the nine river basins as a result

20 of their high frequency. 

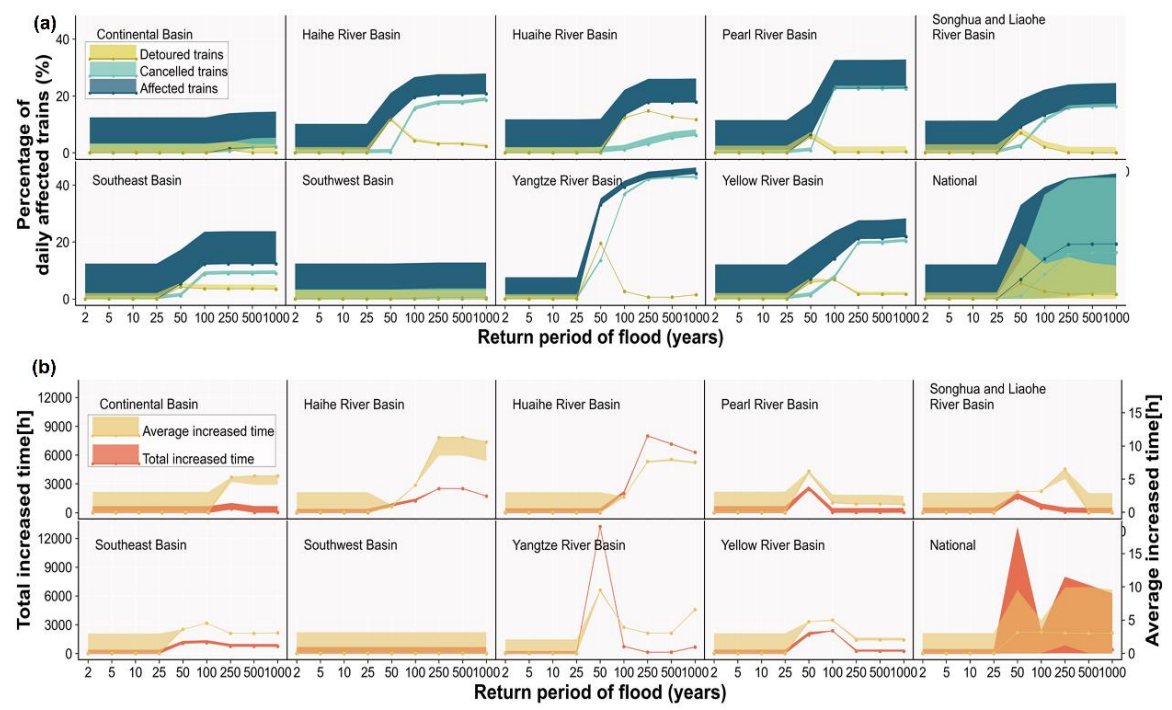

Fig. 7 System vulnerability curves induced by river floods from the national flood event set, showing: (a) the percentage of daily affected trains to the total number of daily trains and; (b) the increased time for the detoured trains. The shading shows the distribution of the flood performance loss, where the lines refer to the median performance loss value and the bounded lines refer to the 10th and 90th percentiles. In the Appendix Fig. A5, we provide the system vulnerability curves for the passenger-level metrics. NB: for total increased travel time, the values can decrease at higher return periods - this is because some of the trains are cancelled and therefore there is no travel time for those trains Due to the different definitions and focus of each metric, the relationship between each metric and flood intensity is also different. From Fig. 7a, we can see that the percentage of daily affected trains and daily cancelled trains to the total number of daily trains increases with the increases of the return period of the flood events for the nine basins. The percentage of daily detoured trains to the total number of daily trains and the total and average increased time for detoured trains do not always increase with 
1 increasing return period shown in Fig. 7a and Fig. 7b. The median performance loss for

2 the five metrics is close to zero for floods with a return period below 25 -years and

3 remains stable when the flood hazard return period exceeds 100 -years because of the

4 railway design protection standards and assumed drainage capacity. Between the 25-

5 year and 100-year flood events, the percentage of daily affected trains and daily

6 cancelled trains relative to the total number of daily trains per flood event increases.

7 The percentage of daily detoured trains relative to total daily trains and the total and

8 average increased time, increases between the 25-year and 50-year flood events, and

9 sharply decreases between the 50-year and 100-year events, especially for the Yangtze

10 River, Yellow River and Pear River Basin floods. This is because most of the north-south

11 rail lines in China, such as the Beijing-Guangzhou and Beijing-Jiulong lines, cross these

12 basins. Most trains that are detoured for a 50-year event cannot be detoured for a 100-

13 year event, as most of the north-south rail lines suffer failures at this hazard intensity.

14 When comparing the results between the nine river basins, we find that, in general,

15 floods in the basins in central and eastern China have the highest impacts on the

16 Chinese national railway system. The percentage of daily affected trains (cancelled and

17 detoured trains) of the total number of trains is the largest for the Yangtze River Basin,

18 followed by the Pearl River Basin and the Yellow River Basin. In the Yangtze River Basin,

19 the median percentage of daily affected trains (cancelled and detoured trains) to the

20 total number of trains is close to $40 \%$ for a 100 -year flood event. For the Continental

21 and Southwest Basins, the value is close to zero. The high impacts of daily affected trains 
1 observed in the central and eastern area are due to a significantly higher railway line

2 density and daily train flows compared to the more inland river basins (see Fig. 3). The

3 higher annual failure probability of the rail segments in the central and eastern regions

4 shown in Fig. 4 also causes a large chance of failed railway segments per flood event

5 and results in higher impact. The daily detoured trains in the Huaihe and Haihe River

6 Basins in eastern China are higher compared to other basins, which leads to a large total

7 increased time when one flood occurs. The reason is that the Huaihe and Haihe River

8 Basins are located in eastern China and only cross railway lines in the eastern coastal

9 area; therefore, the affected trains have more detour options through the lines of the

10 Yangtze and Yellow River Basins, which lead to more detoured trains and associated

11 total increased time.

\section{$12 \quad 3.4$ Risk uncertainty and parameters sensitivity}

13 Figure 8 and Appendix Fig. A6 present the sensitivity of the results to the assumed

14 parameters and the range of performance metric uncertainty. Overall, from the

15 uncertainty histograms, we can see that all the performance metrics are right-skewed,

16 especially for the average daily affected and affected passengers shown in Fig. 8a and c,

17 and average daily cancelled trains and cancelled passengers shown in Appendix Fig. A6b

18 and d, they have a long right tail for high performance loss estimates. This seems a little

19 bit less for the average daily detoured trains and passengers showed in Appendix Fig.

20 A6a and c, and average increased time for detoured trains showed in Fig. 8e, which is 
1 probably the result of the assumption that detouring is impossible when the increased

2 time for re-routing is greater than 24 hours, resulting in a smaller range of detoured

3 options and thus a smaller range in resulting performance loss estimates. The average

4 number of daily affected trains ranges from 100 to 500 trips; for daily affected

5 passengers, it is range from 100,000 to 450,000 people, and the average increased time

6 ranges from 3.5 hours to 5.5 hours with the change in the parameters. The results show

7 that the performance loss estimates are particularly sensitive to the values used for the

8 design standards; using the different parameter settings, we see a variation in the

9 design standards of approximately $43 \%$. The variation in the drainage capacity rate and

10 water level threshold produces similar uncertainty as the capacity loss, which is

11 approximately $28 \%$.
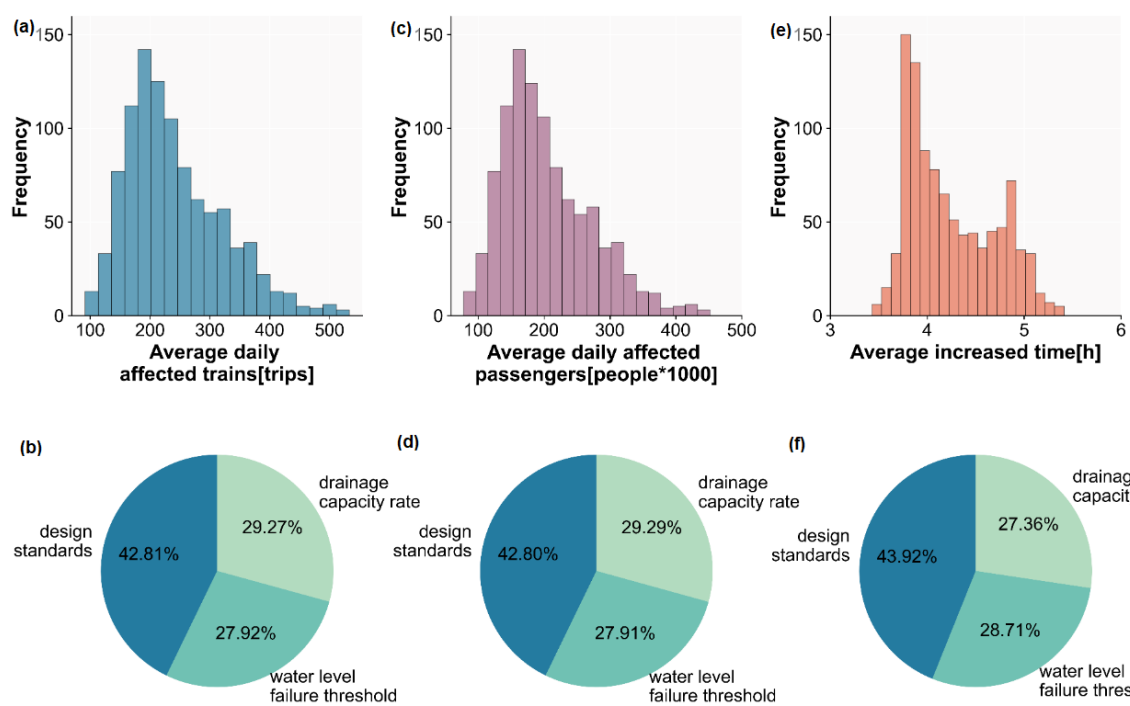

(d)

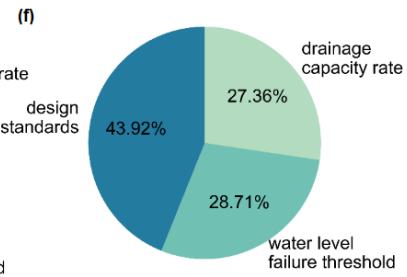

Fig. 8 Results of the uncertainty (histograms) and sensitivity (pie charts) analyses for the performance metrics. (a) and (b) average daily affected trains; (c) and (d) average daily 
affected passengers; (d) and (f) average increased time. Fig. A5 provides the results of

\section{Discussion} high annual failure probabilities are mainly located in the Yangtze River Basin, Southeast Basin, and Pearl River Basin. Comparing the failure probability from this study with the susceptibility map presented in seminal works by Liu et al. (2018a, 2018b), we find some

8 differences in hotspots in Xinjiang Province and along the Beijing-Shanghai line. In our

9 study, we find lower failure probabilities relative to the work of Liu et al. For other

10 regions, the spatial patterns are similar. Our study considers the same protection

11 standards (the water level failure threshold, drainage capacity rate, and design standard)

12 for the railway lines in the Chinese railway system. It should be noted that these

13 standards will not remain constant over time, as a result of ageing infrastructure. This

14 means that the failure probability in some areas in this study is biased compared to

15 research based on historical data. Indeed, many older lines have been

16 upgraded/improved so that the protection standards are more consistent with newer

17 lines.

18 In our work, we find that in the Yangtze River Basin, the median relative cancelled

19 trains to total daily trains is between 0 and $14 \%$ when the flood intensity is between 25

20 and 50-year. In 2016, from May to July, the Yangtze River Basin and Huaihe River Basin

21 suffered by severely rainfall (Lyu et al., 2018). In most affected areas within the Yangtze 
1 River Basin, the floods that occurred exceeded the 25-year return period. Floods caused

2 disruptions on several railway lines, including the Chengdu-Chongqing line, Hefei-

3 Jiujiang line, and Sichuan-Guizhou line, that cross the Yangtze River Basin. In the Huaihe

4 River Basin, damage occurred to the Beijing-Guangzhou line. From 30 June to 6 July,

5 approximately 100 trips (approximately $2 \%$ of the daily trains) were cancelled every day

6 for the Chinese railway system. These observed impacts are within the range of our

7 estimates.

8 In this study, we assumed that within a river basin, the flood probability is constant,

9 whilst among different basins it is fully independent. In future work, we will assess the

10 dependence structure of flood hazards within and between basins, for example, by

11 means of the copula approach as presented in (Jongman et al., 2014). As we assumed

12 a disruption time of one day due to the lack of information on flood duration in this

13 study, we may have underestimated the operational performance losses.

14 Using our current approach, the performance loss can be used as the start of the

15 indirect risk assessment from the travel journey perspective. By combining the ticket

16 prices and the operating cost per kilometre, the economic loss for the railway company

17 can be calculated based on the affected trains and associated passengers (Lamb et al.,

18 2019). As a key mode of transport for interregional trade, the failure of railway systems

19 can produce large shocks for industries dependent on the supply that may come from

20 flooded businesses. The risk values per province (such as expected daily cancelled trains

21 and passengers) can be used as indicators to link with business disruptions. Future work 
1 can try to assess the interregional trade based on the Input and Output table and

2 regional railway transportation performance decreased in this work. The assessment of

3 shocks and indirect economic losses induced by railway system failures is essential for

4 policymakers to design railway infrastructures and to measure indirect economic losses.

\section{Conclusion}

6 The increased frequency of extreme flood events, coupled with interregional trade

7 growth, requires national- and global-scale transportation networks to be more resilient

8 to cope with disruptive events. Evaluation of system-level vulnerability and

9 identification of risk hotspots is a first step to enhance the robustness of the transport

10 system. This study presents a framework for performing system-level vulnerability and

11 risk assessments of a railway system under flooding. The developed framework couples

12 simulated flood events with state-of-the-art network analysis to measure system

13 disruptions caused by floods to identify risk hotspots. This work quantifies the system

14 vulnerability and risk in terms of the performance loss of the Chinese railway system,

15 induced by the flooding. Results show that failure hotspots, system vulnerability and

16 the risk of the Chinese railway system under floods are highly heterogeneous. In

17 addition, the adopted vulnerability metrics present different results in terms of the

18 system vulnerability and risk.

19 High failure hotspots are mainly distributed in South China, i.e. Yangtze River, Pearl

20 River and Southeast Basins. The humid subtropical climate and severe flood hazards in 
1 these areas result in large chances of disruption. For the system vulnerability, the

2 heterogeneity is largely due to a spatially imbalanced railway topology and traffic flow

3 as well as a spatially heterogeneous hazard intensity distribution among China. In

4 general, floods in the basins in central and eastern China have the highest impacts on

5 the Chinese railway system. Floods in the Yangtze River Basin have the largest impact

6 on the daily cancelled trains and associated daily cancelled passengers. In the Yangtze

7 River Basin, the median percentage of daily affected trains to the total number trains

8 can reach to $45 \%$ for a 1000-year flood event. In addition, floods in the Huaihe and

9 Haihe River Basins cause the largest number of the detoured trains as well as associated

10 increased time for the Chinese railway system compared with other basins. Finally, this

11 work quantifies the performance risk due to flooding at the national and provincial level.

12 We find that, at a national level, the average daily number of affected trains and

13 passengers are approximately 200 trips and 165,000 people ( $2.7 \%$ and $2.8 \%$ of the total

14 daily numbers of trains and passengers), respectively. The mean average increased time

15 for detoured trains reaches approximately 5 hours. At the provincial level, the provinces

16 in Central China have the highest absolute and relative risks, estimated to be over 40

17 daily affected trains (4.5\% relative to the number of the province's daily trains) and

18 more than 35,000 daily affected passengers (3.5\% relative to the number of the

19 province's daily passengers). The high risk in terms of the total increased time is mostly

20 distributed in East China, whereas the highest average increased time is distributed in

21 western provinces, such as Xinjiang and Tibet Provinces. The developed system 
1 vulnerability curves and flood risk maps can provide the information for the decisions

2 on safety and effectiveness of operation and maintenance. Various performance

3 metrics can be considered by management departments based on their particular

4 problems.

5 Code/Data availability

6 Supporting data are accessible through the associated reference. The data in this study

7 were analyzed with Python package, and the figures were created with ArcViewTM GIS

8 and Python packages. All codes used in this work are available upon request.

\section{Author contribution}

10 Kai Liu and Weihua Zhu developed the original idea and designed the analyses. Philip

11 Ward and Elco Koks contributed to the study design. Weihua Zhu, Kai Liu and Elco Koks

12 conducted the analysis. Weihua Zhu wrote the original manuscript, and Kai Liu, Ming

13 Wang, Philip Ward and Elco Koks provided comments and revised the manuscript. All

14 the coauthors contributed to scientific interpretations of the results.

\section{Declaration of Competing Interest}

16 The authors declare that they have no known competing financial interests or personal

17 relationships that could have appeared to influence the work reported in this paper.

\section{Acknowledgments}

19 This work was supported by the National Key Research and Development Plan [grant 
1 number 2018YFC1508802]; the National Natural Science Foundation of China [grant

2 number 41771538]; and PJW received funding from the Dutch Research Council (NWO),

3 in the form of a VIDI grant [grant number 016.161.324]. EEK received funding from the

4 Dutch Research Council (NWO), in the form of a VENI grant [grant number

5 VI.Veni.194.033]. The financial support is highly appreciated.

\section{References}

7 Alfieri, L., Burek, P., Dutra, E., Krzeminski, B., Muraro, D., Thielen, J. and Pappenberger, F.: GloFAS-global ensemble

8 streamflow forecasting and flood early warning, Hydrol. Earth Syst. Sci., 17(3), 1161-1175, doi:10.5194/hess-17-

$9 \quad 1161-2013,2013$.

10 Arnell, N. W. and Gosling, S. N.: The impacts of climate change on river flood risk at the global scale, Clim. Change,

11 134(3), 387-401, doi:10.1007/s10584-014-1084-5, 2016

12 Becker, A. and Grünewald, U.: Flood Risk in Central Europe, Science (80-. )., 300(5622), 1099, 2003.

13 Benn, J.: Railway bridge failure during flooding in the UK and Ireland, Proc. Inst. Civ. Eng. Eng., 166(4), 163-170,

142013

15 Chang, H., Lafrenz, M., Jung, I. W., Figliozzi, M., Platman, D. and Pederson, C.: Potential impacts of climate change

16 on Flood-Induced Travel Disruptions: A Case Study of Portland, Oregon, USA, Ann. Assoc. Am. Geogr., 100(4), 938-

17 952, doi:10.1080/00045608.2010.497110, 2010

18 CRPH: High-speed railway emergency response plan., 2012.

19 CRPH: Code for design of railway earth structure, TB10001, 2016.

20 Dottori, F., Salamon, P., Bianchi, A., Alfieri, L., Hirpa, F. A. and Feyen, L.: Development and evaluation of a 
https://doi.org/10.5194/nhess-2021-188

Preprint. Discussion started: 8 July 2021

(c) Author(s) 2021. CC BY 4.0 License. 2001.

5 Editorial Board of China Railway Yearbook, Ed.: China railway yearbook, China Railway Publishing House, Beijing., 2002. Editorial Board of China Railway Yearbook, Ed.: China railway yearbook, China Railway Publishing House, Beijing., 2003.

9 Editorial Board of China Railway Yearbook, Ed.: China railway yearbook, China Railway Publishing House, Beijing., 2004.

11 Editorial Board of China Railway Yearbook, Ed.: China railway yearbook, China Railway Publishing House, Beijing.,

122005.

13 Editorial Board of China Railway Yearbook, Ed.: China railway yearbook, China Railway Publishing House, Beijing.,

142006

15 Editorial Board of China Railway Yearbook, Ed.: China railway yearbook, China Railway Publishing House, Beijing., 2007.

17 Editorial Board of China Railway Yearbook, Ed.: China railway yearbook, China Railway Publishing House, Beijing.,

182008. Editorial Board of China Railway Yearbook, Ed.: China railway yearbook, China Railway Publishing House, Beijing., 2009.

21 Editorial Board of China Railway Yearbook, Ed.: China railway yearbook, China Railway Publishing House, Beijing., 
https://doi.org/10.5194/nhess-2021-188

Preprint. Discussion started: 8 July 2021

(c) Author(s) 2021. CC BY 4.0 License.

2 Editorial Board of China Railway Yearbook, Ed.: China railway yearbook, China Railway Publishing House, Beijing.,

32011

4 Editorial Board of China Railway Yearbook, Ed.: China railway yearbook, China Railway Publishing House, Beijing.,

52012.

6 Editorial Board of China Railway Yearbook, Ed.: China railway yearbook, China Railway Publishing House, Beijing.,

7 2013.

8 Editorial Board of China Railway Yearbook, Ed.: China railway yearbook, China Railway Publishing House, Beijing.,

92014

10 Editorial Board of China Railway Yearbook, Ed.: China railway yearbook, China Railway Publishing House, Beijing.,

112015

12 Editorial Board of China Railway Yearbook, Ed.: China railway yearbook, China Railway Publishing House, Beijing.,

132016

14 Editorial Board of China Railway Yearbook, Ed.: China railway yearbook, China Railway Publishing House, Beijing.,

152017

16 Espinet, X., Rozenberg, J., Ogita, K. S. R. S., Singh Rao, K. and Ogita, S.: Piloting the Use of Network Analysis and Decision-Making under Uncertainty in Transport Operations: Preparation and Appraisal of a Rural Roads Project in

18 Mozambique Under Changing Flood Risk and Other Deep Uncertainties., 2018. Fraiture, C.: Integrated water and food analysis at the global and basin level. An application of WATERSIM, WATER Resour. Manag. -DORDRECHT-, 2007.

21 GFDRR: Tbilisi disaster needs assessment 2015., 2015. 
1 Gil, J. and Steinbach, P.: From flood risk to indirect flood impact: Evaluation of street network performance for 2008.

Gong, M., Wang, Y., Wang, S. and Liu, W.: Enhancing robustness of interdependent network under recovery based on a two-layer-protection strategy, Sci. Rep., 7(1), 1-13, doi:10.1038/s41598-017-13063-2, 2017. Gouldby, B. and Samuels, P. G.: Title Language of Risk - Project definitions Technical Report, , (May 2014), 2009. Haimes, Y. Y.: On the complex definition of risk: A systems-based approach, Risk Anal., 29(12), 1647-1654, doi:10.1111/j.1539-6924.2009.01310.x, 2009. Hirabayashi, Y., Mahendran, R., Koirala, S., Konoshima, L., Yamazaki, D., Watanabe, S., Kim, H. and Kanae, S.: Global flood risk under climate change, Nat. Clim. Chang., 3(9), 816-821, doi:10.1038/nclimate1911, 2013.

11 Hong, L., Ouyang, M., Peeta, S., He, X. and Yan, Y.: Vulnerability assessment and mitigation for the Chinese railway system under floods, Reliab. Eng. Syst. Saf., 137(January 2018), 58-68, doi:10.1016/j.ress.2014.12.013, 2015. Horacio, J., Ollero, A., Noguera, I. and Fernández-Pasquier, V.: Flooding, channel dynamics and transverse infrastructure: a challenge for Middle Ebro river management, J. Maps, 5647, doi:10.1080/17445647.2019.1592719, 2019. Huang, C. and Nivolianitou, Z, S.: Risk analysis based on data and crisis response beyond knowledge: Proceedings of the 7th International Conference on Risk Analysis and Crisis Response, CRC Press, Athens, Greece., 2019. Janic, M. and Vleugel, J.: Estimating potential reductions in externalities from rail-road substitution in TransEuropean freight transport corridors, Transp. Res. Part D Transp. Environ., 17(2), 154-160, doi:https://doi.org/10.1016/j.trd.2011.09.015, 2012.

21 Jongman, B., Hochrainer-Stigler, S., Feyen, L., Aerts, J. C. J. H., Mechler, R., Botzen, W. J. W., Bouwer, L. M., Pflug, 
https://doi.org/10.5194/nhess-2021-188

Preprint. Discussion started: 8 July 2021

(c) Author(s) 2021. CC BY 4.0 License.

1 G., Rojas, R. and Ward, P. J.: Increasing stress on disaster-risk finance due to large floods, Nat. Clim. Chang., 4(4), case study of the March River flood in 2006 at the Austrian Northern Railway, Nat. Hazards Earth Syst. Sci., 15(11), 2485-2496, doi:10.5194/nhess-15-2485-2015, 2015. Infrastructure Loss (RAIL), Nat. Hazards Earth Syst. Sci., 16(11), 2357-2371, doi:10.5194/nhess-16-2357-2016, 2016.

9 Koks, E. E. and Haer, T.: A high-resolution wind damage model for Europe, Sci. Rep., 10(1), 1-11, doi:10.1038/s41598-020-63580-w, 2020.

11 Koks, E. E., Rozenberg, J., Zorn, C., Tariverdi, M., Vousdoukas, M., Fraser, S. A., Hall, J. W. and Hallegatte, S.: A

12 global multi-hazard risk analysis of road and railway infrastructure assets, Nat. Commun., 10(1), 1-11,

13 doi:10.1038/s41467-019-10442-3, 2019.

14 Kundzewicz, Z., IwonaPińskwar and Robertbrakenridge, G.: Large floods in Europe, 1985-2009, Int. Assoc. Sci.

15 Hydrol. Bull., 2013. Lamb, R., Garside, P., Pant, R. and Hall, J. W.: A Probabilistic Model of the Economic Risk to Britain's Railway Network from Bridge Scour During Floods, Risk Anal., doi:10.1111/risa.13370, 2019.

18 Lavers, D. A., Allan, R. P., Villarini, G., Lloydhughes, B., Brayshaw, D. J. and Wade, A. J.: Future changes in atmospheric rivers and their implications for winter flooding in Britain, Environ. Res. Lett., 8(3), 34010, 2013. 
https://doi.org/10.5194/nhess-2021-188

Preprint. Discussion started: 8 July 2021

(c) Author(s) 2021. CC BY 4.0 License.

1 Lyu, H. M., Xu, Y. S., Cheng, W. C. and Arulrajah, A.: Flooding hazards across Southern China and prospective

2 sustainability measures, Sustain., 10(5), 1-18, doi:10.3390/su10051682, 2018.

3 Marsden, M. J.: Quadratic spline interpolation, Bull. Am. Math. Soc., 80(5), 903-906, doi:10.1090/S0002-9904-

4 1974-13566-4, 1974.

5 Meshram, S. G., Powar, P. L. and Meshram, C.: Comparison of cubic, quadratic, and quintic splines for soil erosion modeling, Appl. Water Sci., 8(6), 1-7, doi:10.1007/s13201-018-0807-6, 2018.

7 Metropolis: The beginning of the Monte Carlo method, Cambridge Press. 1638-1692, 1-20, doi:10.9783/9781512808797-001, 1987. de Moel, H. and Aerts, J. C. J. H.: Effect of uncertainty in land use, damage models and inundation depth on flood damage estimates, Nat. Hazards, 58(1), 407-425, doi:10.1007/s11069-010-9675-6, 2011.

11 De Moel, H., Asselman, N. E. M. and H. Aerts, J. C. J.: Uncertainty and sensitivity analysis of coastal flood damage estimates in the west of the Netherlands, Nat. Hazards Earth Syst. Sci., 12(4), 1045-1058, doi:10.5194/nhess-121045-2012, 2012.

14 Moran, A. P., Thieken, A. H., Schöbel, A. and Rachoy, C.: Documentation of flood damage on railway infrastructure, Data Mobility, pp. 61-70. Springer, Berlin, Heidelb., 81, 61-70, doi:10.1007/978-3-642-15503-1_6, 2010. Newman, M. E. .: Networks An Introduction, Oxford University Press, United States., 2010. Nones, M. and Pescaroli, G.: Implications of cascading effects for the EU Floods Directive, Int. J. River Basin Manag., 14(2), 195-204, doi:10.1080/15715124.2016.1149074, 2016. OpenStreetMap contributors: availabe at: http://openstreetmap.org, last access: 7 May 2019. Pregnolato, M., Ford, A., Wilkinson, S. M. and Dawson, R. J.: The impact of flooding on road transport: A depth-

21 disruption function, Transp. Res. Part D Transp. Environ., 55, 67-81, doi:10.1016/j.trd.2017.06.020, 2017. 
https://doi.org/10.5194/nhess-2021-188

Preprint. Discussion started: 8 July 2021

(c) Author(s) 2021. CC BY 4.0 License.

Prudhomme, C. and Genevier, M.: Can atmospheric circulation be linked to flooding in Europe?, Hydrol. Process.,

[online] Available from: _flood_failures/links/5512efd60cf240060b2df24c.pdf, 2004. Rezvani, Z., Jansson, J. and Bodin, J.: Advances in consumer electric vehicle adoption research: A review and research agenda, Transp. Res. Part D Transp. Environ., 34, 122-136, doi:10.1016/j.trd.2014.10.010, 2015.

9 Rodrigue, J.-P.: The geography of transport systems, Taylor \& Francis., 2016.

11 consequences and the costs and benefits of adaptation, Glob. Environ. Chang., 23(6), 1737-1751, doi:10.1016/J.GLOENVCHA.2013.08.006, 2013.

13 Sene, K.: Flood warning, forecasting and emergency response, Flood Warn. Forecast. Emerg. Response, 1-303,

14 doi:10.1007/978-3-540-77853-0, 2008.

15 Singh, P., Sinha, V. S. P., Vijhani, A. and Pahuja, N.: Vulnerability assessment of urban road network from urban flood, Int. J. Disaster Risk Reduct., 28(December 2017), 237-250, doi:10.1016/j.ijdrr.2018.03.017, 2018.

17 Speight, L. J., Hall, J. W. and Kilsby, C. G.: A multi-scale framework for flood risk analysis at spatially distributed

18 locations, J. Flood Risk Manag., 10(1), 124-137, doi:10.1111/jfr3.12175, 2017. 
https://doi.org/10.5194/nhess-2021-188

Preprint. Discussion started: 8 July 2021

(c) Author(s) 2021. CC BY 4.0 License. doi:10.1088/1748-9326/8/4/044019, 2013. doi:10.1371/journal.pone.0178023, 2017.

8 Winsemius, H. C., Van Beek, L. P. H., Jongman, B., Ward, P. J. and Bouwman, A.: A framework for global river flood

9 risk assessments, Hydrol. Earth Syst. Sci., 17(5), 1871-1892, doi:10.5194/hess-17-1871-2013, 2013.

11 and Crisis Response Beyond Knowledge, pp. 550-556, CRC Press., 2019.

13 initiative of China, Transp. Res. Part E Logist. Transp. Rev., 117, 82-95,

14 doi:https://doi.org/10.1016/j.tre.2017.07.003, 2018. 


\section{Appendix}

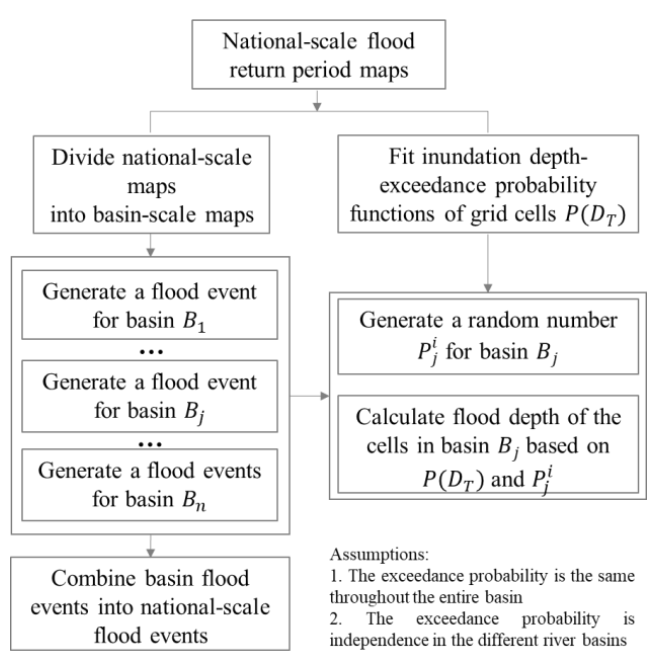

Fig.A1 A flowchart to generate flood event

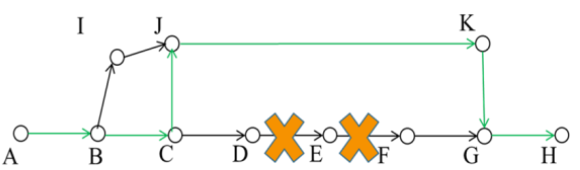

Railway network

Network nodes: $A-K$

Network edges: $A B, \ldots, K G$

Train trips information:

Trip1:A $\rightarrow B \rightarrow C \rightarrow D \rightarrow E \rightarrow F \rightarrow G \rightarrow H$ (passed and stopped stations)

$\mathrm{DE}$ and $\mathrm{EF}$ are disrupted by the flood event.

Two routes can complete the detour:

A-B-I-J-K-G-H

A-B-C-J-K-G-H

Based on the 'Pass the most original stations', the green routes have Been chose for detour.

Fig. A2 An example for detour 

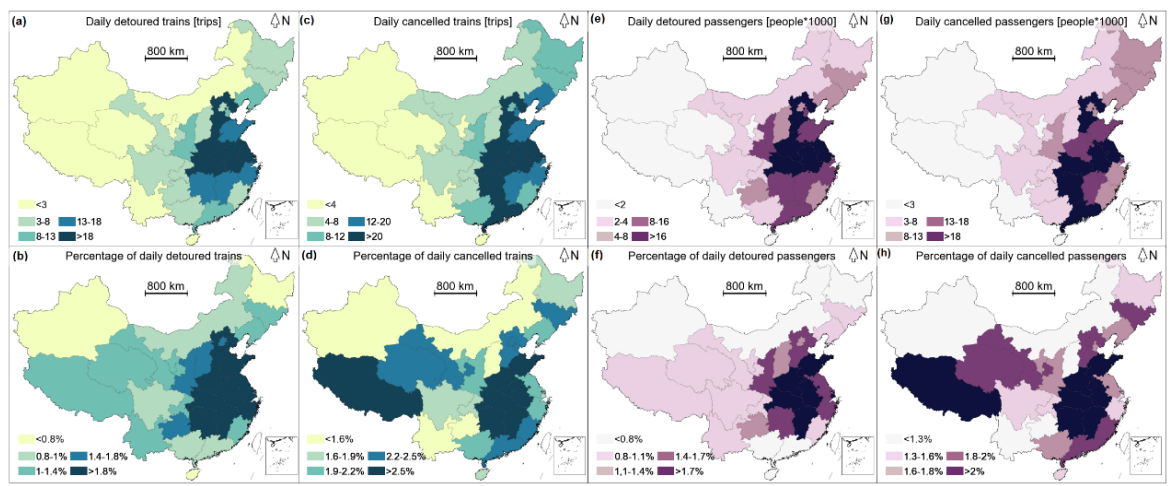

Fig. A3 Performance loss of the railway system per province. (a) presents the daily

detoured trains in absolute terms; (b) presents the daily detoured trains relative to the

number of the province's daily trains; (c) presents the daily cancelled trains in absolute

terms; (d) presents the daily cancelled trains relative to the number of the province's daily detoured passengers relative to the number of the province's daily trains; $(g)$ presents the daily cancelled passengers in absolute terms; (h) presents the daily cancelled passengers relative to the number of the province's daily trains. 


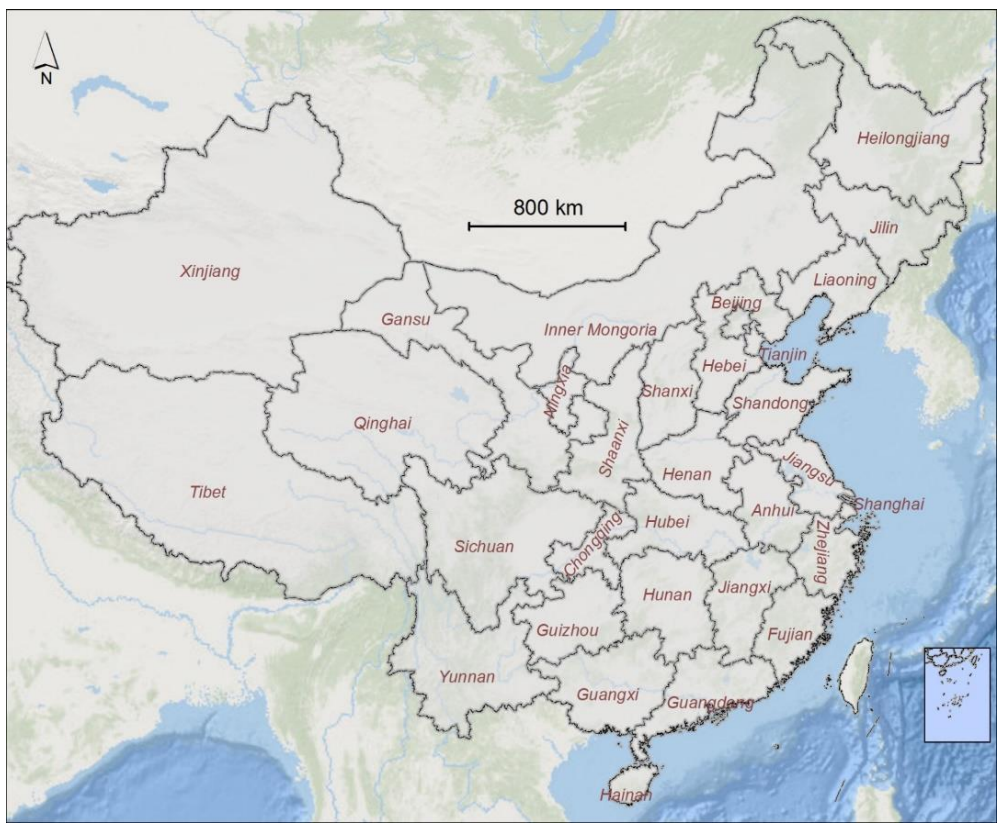

Fig. A4 Chinese provinces distribution map. The China Provincial Map layer comes from

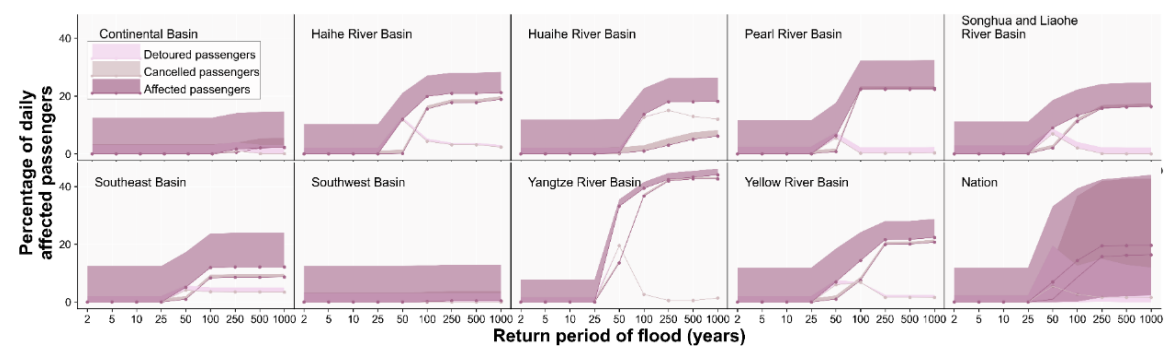

Fig. A5 system-vulnerability curves of passenger's metrics 
https://doi.org/10.5194/nhess-2021-188

Preprint. Discussion started: 8 July 2021

(c) Author(s) 2021. CC BY 4.0 License.

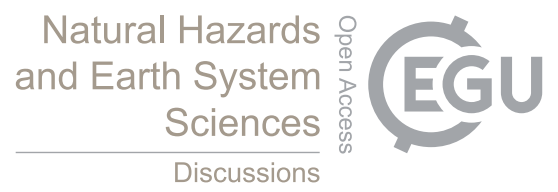

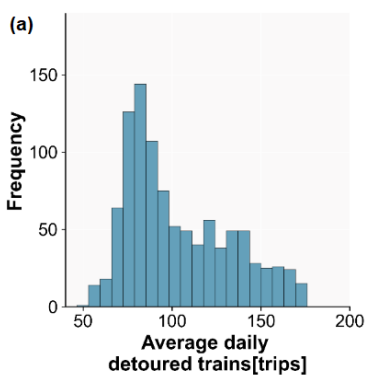

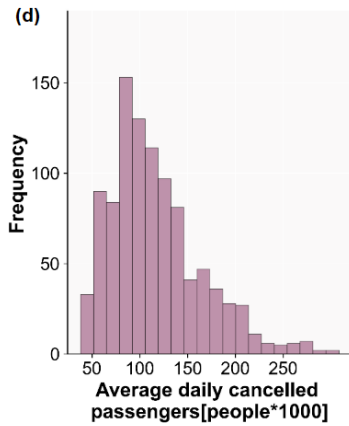

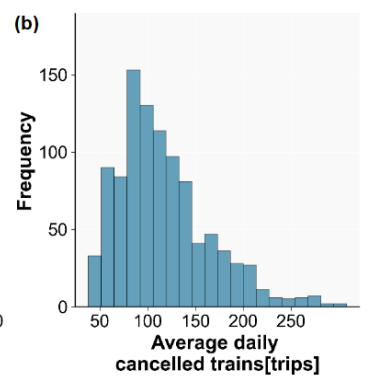

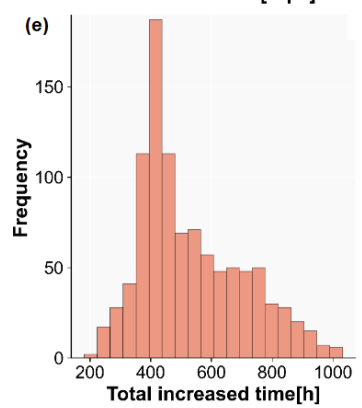

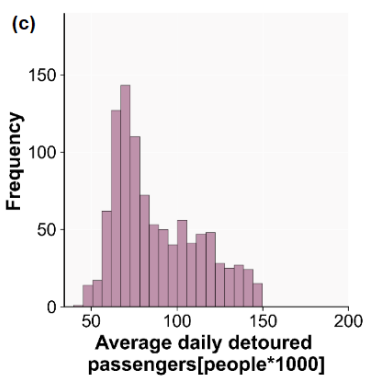

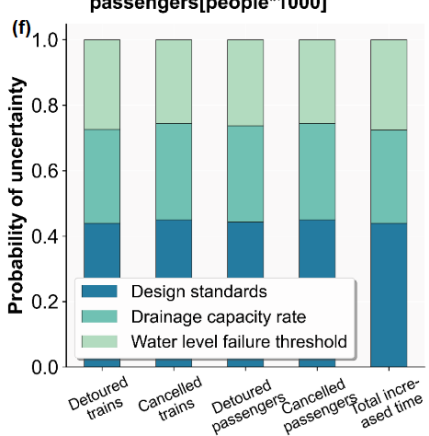

Fig. A6 Results of the uncertainty and sensitivity analyses for the performance metrics.

detoured passengers; (d) average daily cancelled passengers; (e) total increased time; 
Table A1 List of variables

\begin{tabular}{|c|c|}
\hline \multicolumn{2}{|c|}{ List of variables } \\
\hline Variable & Description \\
\hline$T$ & Return period of $T$ - year \\
\hline$D_{T}$ & The flood depth with return period of $T$-year \\
\hline$g_{x, y}$ & A grid cell with longitude $x$ and latitude $y$ \\
\hline$D_{T_{x, y}}$ & The flood depth of a flood event of grid cell $g_{x, y}$ with return period of $T$-year \\
\hline$P\left(D_{T}\right)$ & The annual exceedance probability of flood depth $D_{T}$ \\
\hline $\operatorname{Pr}\left(D_{T}\right)$ & A quadratic, continuously differentiable function of $P\left(D_{T}\right)$ \\
\hline $\operatorname{Pr}_{x, y}\left(D_{T}\right)$ & A set of continuous inundation depth-exceedance probability functions for $g_{x, y}$ \\
\hline$a, b, c$ & Constant parameters in function $\operatorname{Pr}_{x, y}\left(D_{T}\right)$ \\
\hline$B_{j}$ & River basin $j$ \\
\hline$E_{j}^{i}$ & Flood event $i$ in river basin $B_{j}$ \\
\hline$P_{j}^{i}$ & A random number between 0 and 1 for flood event $E_{j}^{i}$ in basin $B_{j}$ \\
\hline$W d$ & The failure threshold of the railway service after drainage, default value is 0.2 \\
\hline$W L_{x, y}$ & The water level after drainage of grid cell $g_{x, y}$ \\
\hline$W l d_{x, y}$ & The water level of the flood depth under design standard of grid cell $g_{x, y}$ \\
\hline Dc & The drainage capacity rate of Chinese railway system, default value is 0.8 \\
\hline$Z(x y)$ & The failure condition of grid cell $g_{x, y}$ \\
\hline$l_{i j}$ & Rail segment between station $i$ and station $j$ \\
\hline$F c_{i j}$ & Failure condition of component $l_{i j}$ \\
\hline$F C_{i j}^{e}$ & The failure condition of railway segment $l_{i j}$ under flood event $e$ \\
\hline$A F_{i j}$ & The annual failure probability of rail segment $l_{i j}$ \\
\hline$E$ & The $\mathrm{N}$-year flood events catalogue \\
\hline$N_{S}$ & The original number of trains in the system \\
\hline$N_{e}^{S}$ & The number of running trains in the system after a flood event \\
\hline$N_{e}^{t o l}$ & The number of daily affected trains under flood event $e$ \\
\hline$N_{e}^{c}$ & The number of daily is cancelled trains under flood event $e$ \\
\hline$N_{e}^{d}$ & The number of daily detoured trains under flood event $e$ \\
\hline$C A_{i}$ & The capacity of the ith train \\
\hline$P_{e}^{t o l}$ & The number of affected passengers \\
\hline$P_{e}^{c}$ & The number of daily passengers is cancelled passengers under flood event $e$ \\
\hline$P_{e}^{d}$ & The number of daily passengers is detoured passengers under flood event $e$ \\
\hline$T_{i}$ & The original travelling time of the $i t h$ train. \\
\hline$T_{i}^{e}$ & The running time of the ith train under flood event e \\
\hline$T_{e}^{t o l}$ & The total increased time for detoured trains under flood event $e$ \\
\hline$T_{e}^{a v e}$ & The average increased time under flood event e \\
\hline$A R_{S}$ & The expected daily flood risk level to the railway system \\
\hline$V_{e}$ & $\begin{array}{l}\text { Performance loss metric, including } N_{e}^{d}, N_{e}^{c}, N_{e}^{t o l}, P_{e}^{d}, P_{e}^{c}, P_{e}^{t o l}, T_{e}^{t o l}, \\
\text { and } T_{e}^{\text {ave }}\end{array}$ \\
\hline
\end{tabular}


https://doi.org/10.5194/nhess-2021-188

Preprint. Discussion started: 8 July 2021

(c) Author(s) 2021. CC BY 4.0 License.

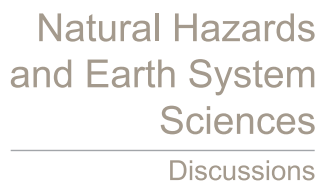

Table A2 List of all assumptions taken in this study and their range in the sensitivity analysis

\begin{tabular}{|l|l|l|}
\hline \multicolumn{3}{|l|}{ List of all assumptions taken in this study and their range in the sensitivity analysis } \\
\hline Varying parameter & Default values & Range \\
\hline water level failure threshold & 0.2 & {$[0.1 \mathrm{~m}, 0.5 \mathrm{~m}]$} \\
\hline drainage capacity rate & 0.8 & {$[0.7,0.9]$} \\
\hline design standards & 100 & {$[50,100]$} \\
\hline
\end{tabular}

2 